Concha \& Toro Vineyard Caves at San Miguel: Unearthing the forgotten
PALABRAS CLAVE • CAVAS ENTERRADAS · ESTRATECIAS DE INTERVENCIÓN AROUITECTÓNICA. PATRIMONIO

KEYWORDS • BURIED WINE CAVES . STRATECIES OF ARCHITECTURAL INTERVENTION · HERITACE

\section{RESUMEN}

Anacronismo en Europa, al momento de su creación en Chile, las cavas enterradas de vino constituyen un reconocido patrimonio que ha sido objeto de evocación romántico-turística, olvido colectivo, o mitificación comunitaria, siendo estos últimos dos, los lugares comunes alternados, del caso de estudio. El presente artículo busca empezar a establecer que el valor y estrategia de intervención arquitectónica en un patrimonio determinado debe considerar categorías adicionales a las convencionales en cuanto a clasificación, valoración histórica-estética, tecnología y gestión.

Lo anterior, como una nueva manera de enfrentar el contexto local de escasez de recursos y precariedad normativa para abordar proyectos de rehabilitación de inmuebles patrimoniales. Un contexto actual donde los intereses inmobiliarios parecen -a ratossobreponerse a cualquier interés de la comunidad, lo cultural incluido.

\section{ABSTRACT}

Anachronism in Europe, when created in Chile, the buried wine caves constitute a recognized heritage that has been the object of romantic-touristic evocation, collective forgetfulness or community myth, being the latter two, alternate commonplace of this case study.

The present article seeks to begin establishing that the value and strategy of an architectural intervention in a given heritage should consider additional categories other than the conventional ones in terms of classification, historic-aesthetic value, technology and management

This, as a new way of facing the local context of resource shortage and normative precariousness to address the rehabilitation projects of heritage buildings given the current context where developer's interests seem, at times, to overpower any community interest, cultural heritage included.

\title{
Cavas Viña Concha y Toro en San Miguel: desenterrando lo olvidado
}

\author{
FELIPE GALLARDO GASTELO*·Universidad de Chile, Chile·felipe.gallardogastelo@gmail.com
}

Fecha de recepción: 30 de agosto 2017 - Fecha de aceptación: 16 de octubre 2017

\section{INTRODUCCIÓN}

Las cavas subterráneas o enterradas constituyen un objeto de investigación reciente y escasamente abordado, donde, a pesar de ser aparentemente invisibles, el desarrollo inmobiliario las hace aparecer, en el desarrollo de su intromisión en el subsuelo.

Se estima que en Santiago existen al menos una decena de cavas subterráneas construidas en el siglo XIX; siendo la comuna de San Miguel un ejemplo de existencia de este patrimonio que convoca la producción vitivinícola de la actual área metropolitana de la ciudad de Santiago. La pregunta actual es cómo integrar en términos reales, contemporáneos a la luz de una gestión innovadora, en tanto ausencia de referentes, este patrimonio a la realidad cotidiana y local de nuestra ciudad.

Una casuística particular, se despliega a partir del problema de la construcción de un conjunto residencial de edificación en altura, sobre los hallazgos de la cava Concha y Toro, ubicados en lo que fuera el Llano Subercaseaux, para lo cual se desplegó una estrategia público-privada que involucró autoridades e instituciones del Estado, en una operación de recuperación patrimonial, que se llevó a cabo siguiendo una metodología de puesta en valor, mediante proyecto de rehabilitación arquitectónica para una integración a la comunidad y la institucionalidad municipal incluyendo una gestión de comodato de espacios públicos.

\section{METODOLOGÍA}

La metodología para la puesta en valor consistió en el desarrollo de un proyecto de intervención para lo cual se consideró una fase de investigación y una fase relacional con el diseño, donde se definieron las siguientes etapas:

\section{INVESTIGACIÓN HISTÓRICA}

Tuvo como fin conocer a cabalidad el bien inmueble, en este caso las cavas subterráneas, lo que se realizó mediante una metodología cuantitativa y cualitativa. Lo primero en pos

* Licenciado en Arquitectura, Arquitecto y Magíster en Urbanismo por la Facultad de Arquitectura y Urbanismo de la Universidad de Chile. DEA conducente a Doctorado en la Universidad Politécnica de Madrid, España. Académico de la Universidad de Chile con especialización en el área Urbanismo, Patrimonio Arquitectónico y Restauración. Es autor y coautor de diversos proyectos y obras de restauración, entre ellas: Antiguas Cavas Viña Concha y Toro (2016), Teatro Municipal de Traiguén (2012), Teatro Municipal de Lanco (2012), Casas Santa Rosa de Apoquindo (Municipalidad de Las Condes, 2008), Hotel 33 Latitud Sur (Valparaíso, 2008) y Museo de Arte Contemporáneo (Navarrete Arquitectos, 2005). 
1. Esquema de ubicación de las cavas de San Miguel, ex Viña Concha y Toro. Elaboración del autor.
2. Levantamiento planta general de las cavas de San Miguel, ex Viña Concha y Toro. Elaboración del autor.
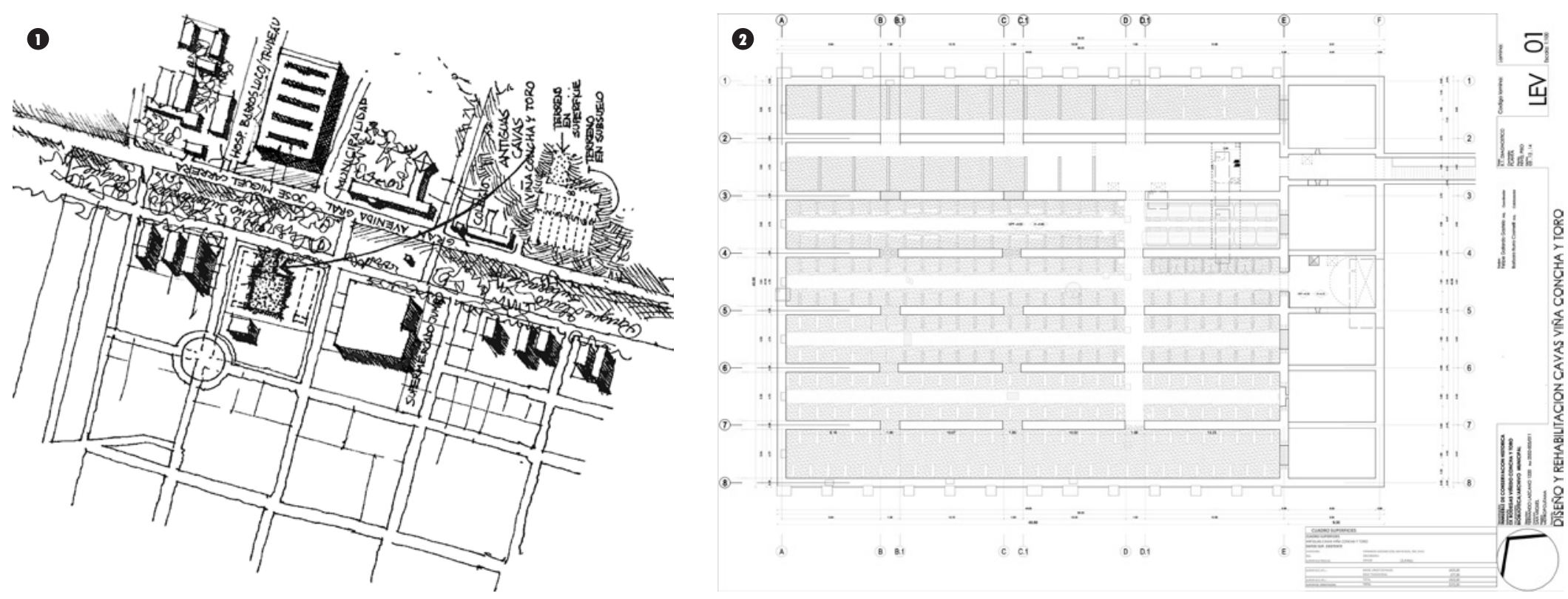

de un levantamiento métrico y relevamiento físico del inmueble, para así estudiar sus características estético-formales y constructivas. Lo segundo, para conocer el contexto histórico, social, cultural, político y económico en el cual el conjunto patrimonial se gestó, desarrolló y asimismo, para comprender su estado actual.

\section{VALORIZACIÓN Y DISCRIMINACIÓN DE COMPONENTES ARQUITECTÓNICOS}

Esta etapa consistió en la distinción de los diversos componentes de las cavas; la discusión de una taxonomía axiológica adecuada y la ponderación de sus elementos constitutivos, a la luz de los distintos valores definidos, que para el caso de estudio fueron: lo histórico, urbanístico, arquitectónico, estético y social (Villagrán, 1989).

\section{DIAGNÓSTICO DE ESTADO DE CONSERVACIÓN}

El diagnóstico de las cavas fue relevante por cuanto contribuyó a definir el estado de conservación del bien inmueble, incidente en la determinación del programa arquitectónico y distribución de recintos. Consistió en la comprensión del estado de la construcción actual como una sintomatología que redunda en un diagnóstico. En este sentido, es básico consignar el estado de la estructura por las implicancias para la estabilidad del bien, y la detección de los distintos tipos de deterioro, sus causas, y su comprensión como conjunto y sistema.

\section{CRITERIOS DE INTERVENCIÓN}

De las etapas anteriores, se deduce una propuesta de intervención, considerando las posibilidades de preservación de sus valores; su óptima conservación material, y las implicancias modificatorias, de carga de uso y de incorporación de equipos y condiciones tecnológicas, que el nuevo uso implica. Todo lo anterior en base a criterios de actuación tecnológico-constructivo internacionales reconocidos por la autoridad internacional (UNESCO, 1994).

\section{RESULTADOS DEL PROCESO DE PUESTA EN VALOR}

\section{ASPECTOS HISTÓRICOS}

La investigación histórica relevó diversos aspectos de las bodegas enterradas de vino y el desarrollo del sector en que se ubican, como por ejemplo que estas corresponden a una expresión de la arquitectura industrial que apareció de manera contundente y clara, en la forma de bóvedas de cañón rebajado y crucería en la segunda mitad siglo XIX, como producto del auge de la vitivinicultura nacional, a su vez producto del auge en obras públicas y de la diversificación económica de los intereses locales asociados a la industria minera (González, Zavala \& Montandón, 1975).

El auge descrito se dio en general por cuatro factores, que determinaron el surgimiento de las cavas. Primero, el cambio de la producción vitivinícola que incluyó las cepas francesas. Hasta 1851, el vino se producía con uvas de procedencia colonial, en procesos muy variables, generándose calidades heterogéneas 
3. Imagen del estado original de una de las cavas en junio del 2015. Elaboración del autor.

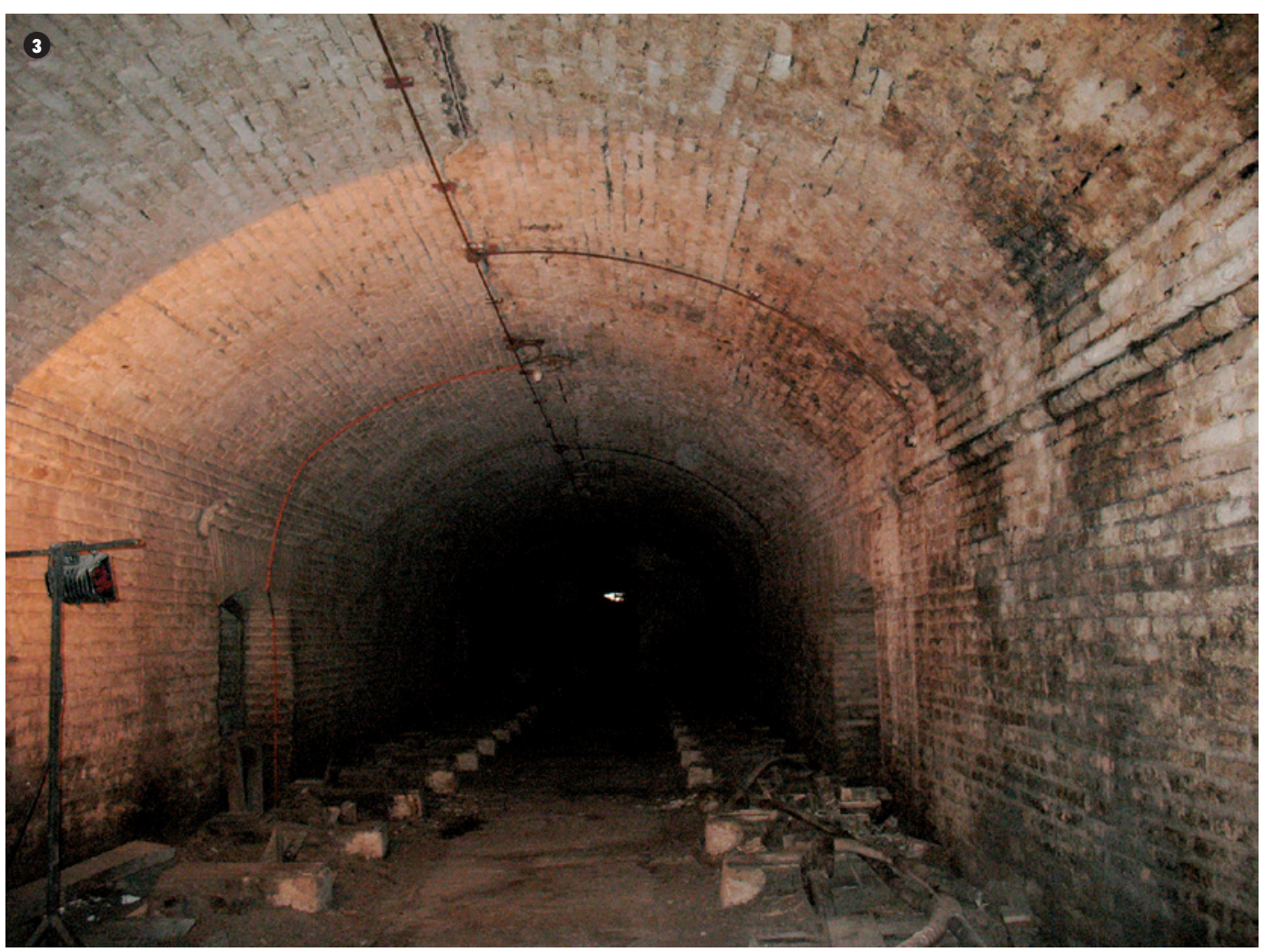

de vino. Con la llegada a Chile del enólogo francés M. Bertrand, a instancias del vitivinicultor Silvestre Ochagavía Echazarreta, se introdujeron al país cepas francesas de vino (Del Pozo, 2014).

Segundo, se modificaron las técnicas de producción del vino local, proceso acontecido junto con la introducción de cepas y enólogos franceses -con la intención de asimilar los sistemas de elaboración de vino de la Francia de la época-, traduciéndose en mejoras en la calidad del vino, y en la conformación de un modelo empírico de trabajo que las viñas chilenas fueron adoptando tomado de las técnicas francesas (Ceballos, 2014).

Tercero, la adaptación positiva que algunas cepas francesas experimentaron, como las Burdeos y Borgoña, encontrando en el medio chileno condiciones ecológicas (suelo, lluvia, asoleamiento, clima, entre otros) similares y
4. Imagen del estado original de una de las cavas incluyendo las barricas en junio del 2015. Elaboración del autor.

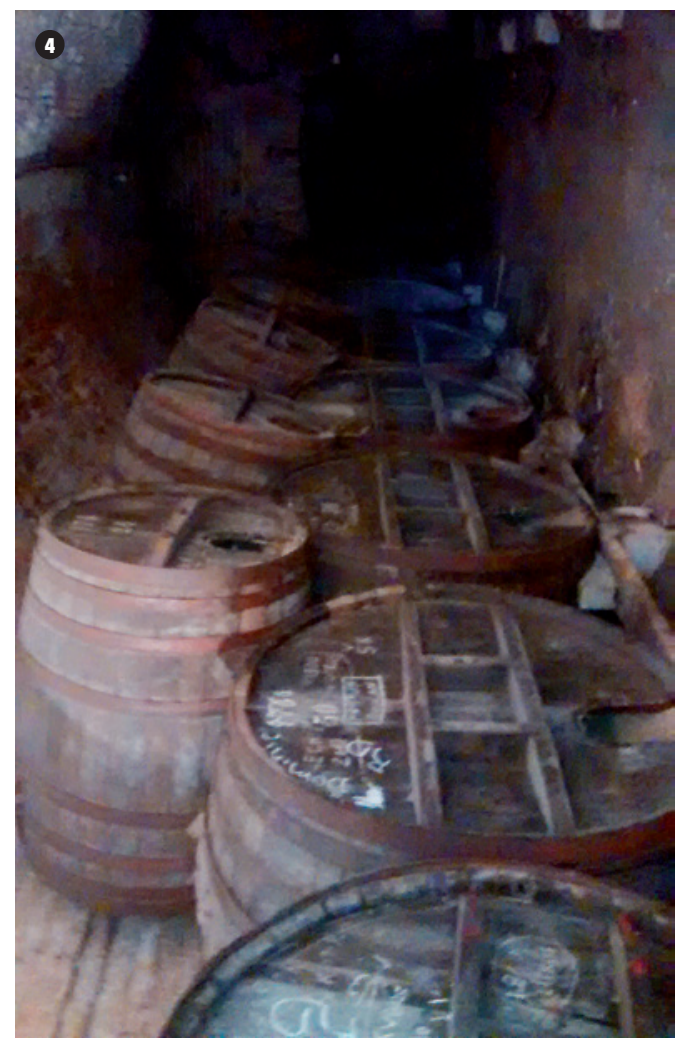

de Chile, en 1875, situación que introdujo en la agricultura nacional nuevas técnicas y consecuentemente, formas de almacenamiento que respondieron a un nuevo requerimiento espacial.

Cuarto, en una dimensión sociocultural, el auge minero del período 1860 a 1880, repercutió doblemente en el desarrollo de las cavas subterráneas. Por una parte, las familias cuyas fortunas se habían formado en la explotación de yacimientos en Copiapó, Coquimbo, Carrizal, entre otros, vieron la inversión en viñas como un medio de prestigio social, a la vez que una buena alternativa de diversificación de su actividad económica. Por otra parte, el desarrollo minero permitió un auge de obras públicas, desde canales de regadío hasta líneas de ferrocarril, infraestructura que influyó positivamente en la explotación y logística de la industria vitivinícola. Lo anterior de hecho se tradujo en la primera exposición Internacional Ganadera, Agrícola e Industrial de Santiago
De los cuatro factores mencionados, el último clave, implicó la adquisición, explotación y residencia en propiedades agrícolas, y el impulso hacia la inversión y concreción de obras, imitando de manera relevante a la porción de la oligarquía tradicional que había derivado hacia la vitivinicultura. En este contexto descrito, la aparición de la cava subterránea es innovadora, pero tardía:

Las bóvedas subterráneas de ladrillo y piedra construidos en Chile, en el último cuarto del siglo XIX, constituyen una curiosa y feliz supervivencia de un recurso estructural abandonado ya en esa época en Chile y en Europa para construcciones de superficie. 
Queda su uso en las bóvedas subterráneas, pero aún, los países vitivinícolas europeos de más larga tradición en esa actividad no las construyen en ese período porque ya las tenían. Sospechamos que, de no ser así, en casos singulares que también se extiende en otros usos, recurrieron a las bóvedas de cañón corrido y a la de crucería. La aparición de estas bóvedas en Chile está aparejada con la importación de las cepas y las técnicas vitivinícolas francesas. Aun así, la presencia de estas construcciones de técnica romana y románica representan, por la época en que se levantaron, un hecho notable, de relevancia y digna descripción y estudio ... (González, et al, 1975, p. 14).

La construcción de bodegas enterradas de vino implicó, además, un acondicionamiento ambiental controlado y pasivo, expresado en las viñas industriales y en las diversas bodegas privadas, de las cuales es difícil rastrear su cantidad, propietarios y ubicación. Sin embargo se conoce cierta clasificación por escala: la menor, destinada a cava de uso familiar; la mediana, destinada a vinos de guarda-como la que se encuentra bajo la Casa de la Cultura de San Miguel; y la de gran envergadura industrial, destinada al almacenamiento, guarda y maduración de vinos y que adquieren importantes dimensiones, en torno a los 2.000 $\mathrm{m}^{2}$ o más, como es el caso de las bodegas de vino enterradas de la antigua Viña Concha y Toro en San Miguel.

Para comprender el valor de las cavas enterradas y su condición de elemento referencial en una trama de acontecimientos y personalidades que se distinguen en la historia nacional, cabe señalar que durante la colonia, el sector donde se ubican las cavas, era de tierras yermas y áridas, no aptas para la agricultura, cuya principal característica consistía en contener el camino de la frontera (actual calle San Diego y al sur Gran Avenida José Miguel Carrera), que era el camino al sur del territorio. Este sector había sido adquirido por Gaspar Banda en 1595, y luego vendido

5. Imágenes de la superposición de modelos residenciales en la comuna de San Miguel. Archivo del autor.
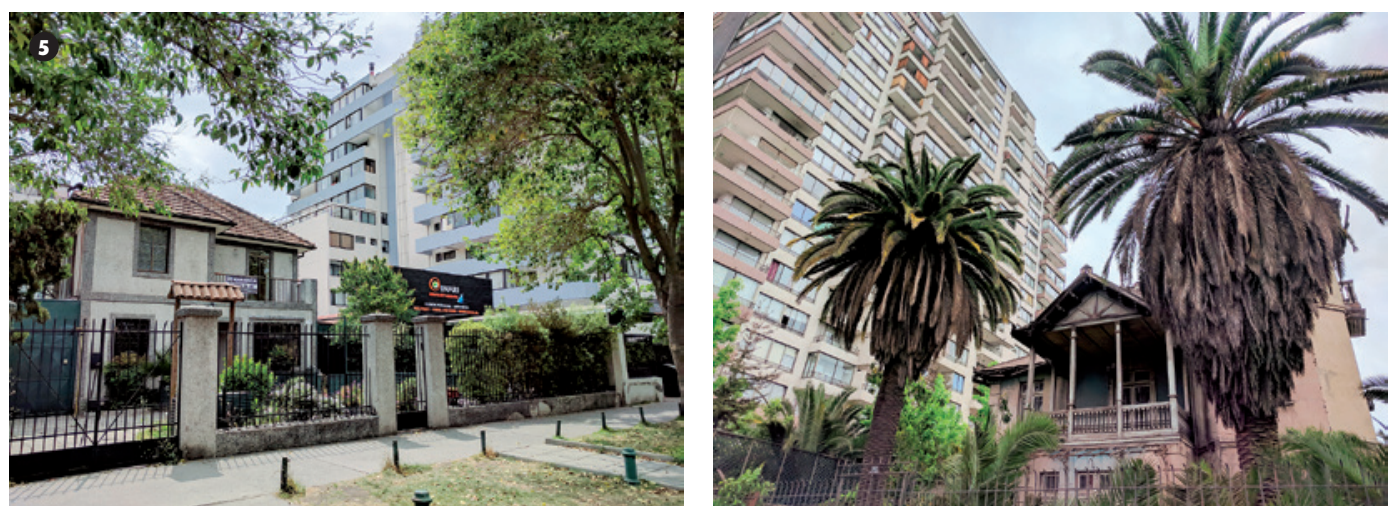

sucesivamente en 1627 y 1650 , siendo utilizado para el descanso del ganado y las carretas que venían desde el sur hacia Santiago, conformando el potrero de Santiago, entre el Zanión de la Aguada y el Río Maipo, por un lado; y entre los faldeos de Ñuñoa y los Cerros de Tango, por otro. En suma, un territorio sin mayor interés, por cuanto su fertilidad para la explotación agrícola, dependía de que se asumieran obras inexistentes de regadío.

No obstante, el agua llegaría. En 1797 el ingeniero militar Agustín Cavallero y el arquitecto Joaquín Toesca, recibieron el encargo del estudio definitivo del Canal San Carlos, labor que se tradujo en un proyecto, aprobado en 1799 por la Real Audiencia, iniciando el desarrollo esporádico de una obra que, tras ser interrumpida durante la guerra de independencia, fue inaugurada en 1820. Durante ese lapso, la tenencia de la propiedad evolucionó llegando a manos de Ramón y José Antonio Subercaseaux Mercado, en 1839.

Comenzó entonces la explotación del terreno, disponiéndose a orillas del camino al sur (tangencial a la propiedad) cuartos de servicio; bodegas y casas de cuidadores; una casa patronal para la familia; criaderos de plantas; jardines; y otras acciones, modificaciones, y ampliaciones. En 1849 se cedió la faja paralela al camino al sur, lugar en el que se hizo común -por su topografía plana y uniforme- para carreras a la chilena, a la espera de las carretas desde el sur, antes de entrar a la ciudad.
Con la introducción de cepas francesas en la vitivinicultura, desde 1851, Ramón Subercaseaux convirtió su chacra en una Viña, contratando para ello al viñatero francés Louis-Joseph Bachelet, quien arriba en 1860 (Ceballos, 2014).

Bachelet proyectó nuevas bodegas, cavas subterráneas y otras instalaciones, fomentando con ello el auge de la Viña; empresa que se consolidó en 1862, con el matrimonio de Emiliana Subercaseaux Vicuña con Melchor Concha y Toro, quien a sus bienes incrementó la herencia de su esposa en Pirque, dando lugar a la Viña Concha y Toro. Con el cambio de siglo, la Viña se perfilaba como una de las principales de Santiago. Se estima que en esa época comprendía 94 hectáreas. Se construyeron cavas de ladrillo unidos con clara de huevo; una de ellas bajo la casona de la familia y otra bajo la bodega de la viña, ambas existentes hasta hoy (Giulasanti, 1987, p. 11).

No obstante, a la muerte de Ramón Subercaseaux Vicuña, en 1937, la viña se disgrega, comenzando un paulatino período de subdivisión y venta con fines inmobiliarios, un proceso ya anunciado en 1908, con la llegada del tranvía a la comuna. La empresa familiar concentró sus esfuerzos en las Viñas de Pirque, destinando la propiedad de San Miguel a una producción más reducida y, especialmente, al almacenamiento y distribución.

Gradualmente la propiedad se enclaustra, se confina mediante cierros y medianeros 
6. Láminas del levantamiento planimétrico de las cavas. Elaboración del autor.

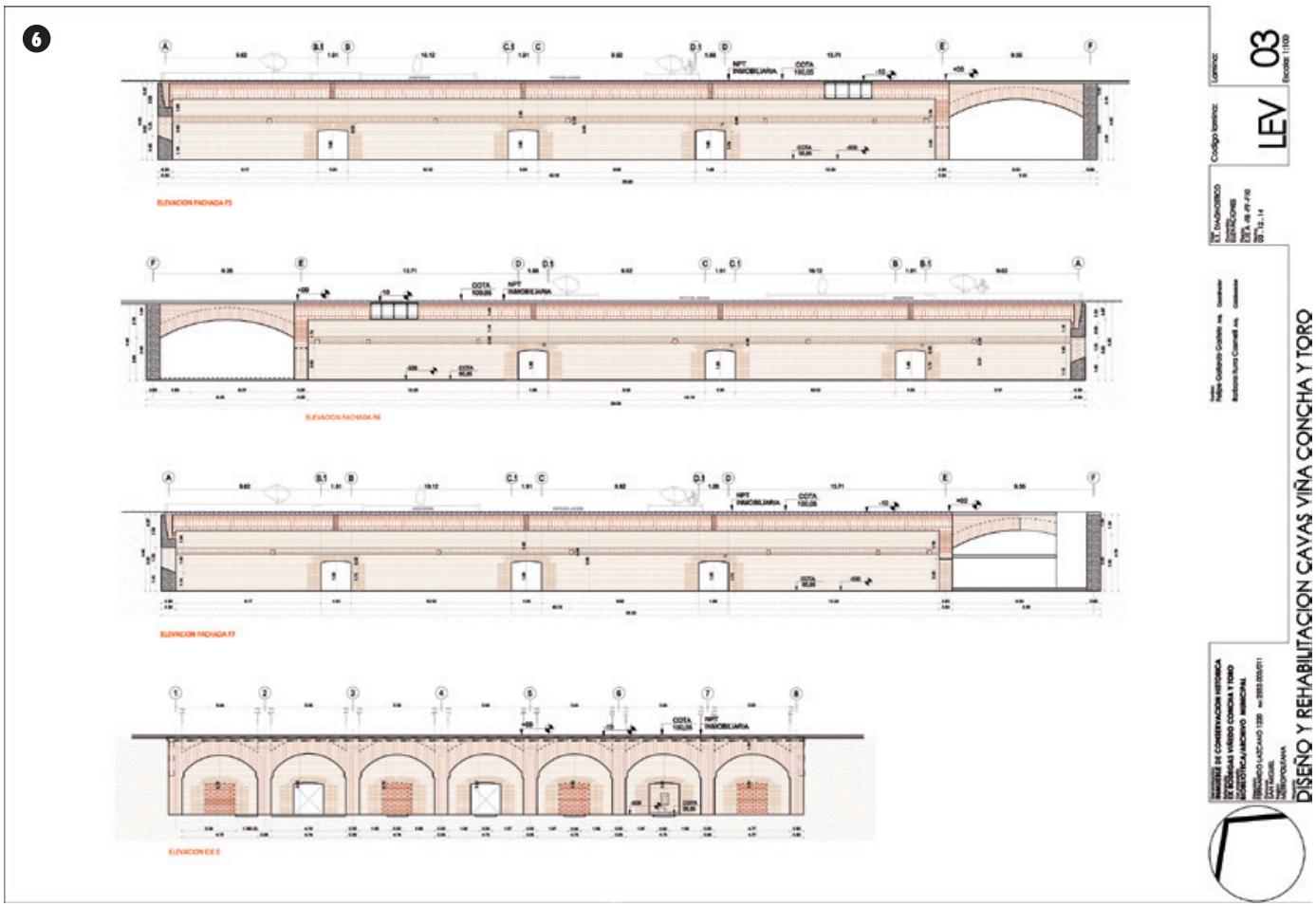

acompañando la conformación urbana del sector durante el siglo XX, primero bajo un modelo de ciudad jardín y posteriormente en los comienzos del siglo XXI coexistiendo con la vivienda colectiva en altura, siendo un elemento de valor patrimonial para la comuna.

El levantamiento planimétrico develó ocho bodegas lineales de 4,75 metros de ancho, 48,2 metros de largo y 3,80 metros de altura interior, dispuestos contiguamente y conectado por dos bóvedas transversales que posibilitaban el acceso, encontrándose conectadas por una escalera de hormigón cuyo origen se presume posterior a la fecha de construcción de las cavas. El conjunto comprende aproximadamente $2.380 \mathrm{~m}^{2}$ construidos. La estructura soportante es de muros y bóvedas de albañilería artesanal de ladrillo cocido, y mortero de argamasa (base de cal), conformando muros longitudinales cerrados en su parte superior por arcos rebajados. El nivel de suelo en el que se despliega el espacio utilizable de las cavas excede los 5 metros de profundidad, bajo la cota de superficie. Arcos de albañilería casi tangentes al nivel de suelo, separados por el espesor de las bóvedas (85 a 105 centímetros), magníficos trabajos de ladrillo que no vieron la luz por más de medio siglo. Interiormente, las cavas se encontraron ocupadas por 20 barricas que debido a sus dimensiones y a la complementariedad del sistema general productivo, resultaron de gran valor en la comprensión del espacio.

En el año 2012, la propiedad fue adquirida construcción de un proyecto de vivienda en altura, momento en el cual se evidenció tanto a las autoridades administrativas como a la comunidad cercana de vecinos y habitantes de la comuna, la existencia de estas estructuras enterradas. En esta etapa, la gestión municipal logró un comodato y la tenencia del bien por casi cien años siendo designado a un proyecto de equipamiento cultural que comprenderá en lo futuro, principalmente la biblioteca municipal. por desarrolladores inmobiliarios, para la

\section{VALORES}

Las cavas enterradas nos remiten al pasado agrícola comunal, en un sentido amplio, los terrenos de las cavas, son el embrión de la comuna siendo uno de los conjuntos residenciales y asentamientos más antiguo e importante del lugar, desde el cual se remitían productos a Santiago o donde el transporte de mercaderías efectuaba una pausa en su trayecto.

Su antigüedad (entre 1860 y 1883), su condición de residencia y lugar de paso de diversos personajes del acontecer político, social, de la época, sitúa a las cavas enterradas en un lugar de valoración histórica cultural, con una antigüedad de más de 150 años. El conjunto, se complementa con otros vestigios del pasado comunal que conforman hitos referenciales de la ciudad como por ejemplo, el parque Llano Subercaseaux; que determina algunos elementos de trazado urbano; la Casa de Cultura de la comuna de San Miguel, también inmueble que perteneciera a la familia Subercaseaux; entre otros; siendo de esta manera posible de comprender como un hecho urbano (Rossi, 1982).

El valor arquitectónico del conjunto distingue un aspecto estético y otro, tipológico. El primero corresponde a una configuración arquitectónica que define naves, espacios y recorridos conformando una atmósfera (Zumthor, 2006) que incita el interés del espectador o visitante, no solo por la experiencia inusitada de acceder a una cava; sino por efectos físicos como la temperatura, la percepción de los límites, de la luz, de la tectónica (Frampton, 1999) o bien del panorama olfativo, que a pesar de configurar espacios cerrados, desplazan una sensación de encierro, permitiendo la apreciación de la envergadura total de la obra, que suple su carencia de luz natural, con recorridos y grandes dimensiones y fugas visuales, que sorprenden.

Lo segundo, en una aproximación interpretativa a la llamada crítica tipológica (Rossi, 1982) corresponde a lo que podría denominarse el tipo de las grandes bodegas de vino -o cavas- 
enterradas del siglo XIX, una tipología originada en Francia, que adquirió vigencia a mediados del mismo siglo, en Chile. Dicho fenómeno ha sido parcialmente explicado, debido a que los especialistas franceses desconocían de manera exacta y de primera mano, las condiciones del clima local, replicando las formas productivas del procedimiento técnico en su origen, incentivando la construcción de cavas de vino enterradas, que ofrecían una manera clara y conocida de controlar las condiciones ambientales (temperatura y humedad), dentro de parámetros adecuados al almacenamiento y fabricación de vino, son ejemplares. Como se ha mencionado anteriormente, esta dinámica productiva se inscribió en un proceso de poblamiento, de naturaleza fundacional del sector, marcando el desarrollo de la comuna en su organización espacial, ejemplo de ello es el actual Parque Llano Subercaseaux que sirvió, en su tiempo, para la conectividad del transporte productivo.

Tecnológicamente, las antiguas cavas de la Viña Cocha y Toro corresponden, por demás, a un ejemplo de las posibilidades de la albañilería de ladrillo de arcilla artesanal y el mortero de cal y canto, llevados a límites insospechados de forma y envergadura, situación que se traduce, en albañilería continuas, resistentes a importantes sobrecargas, que además aportan un acondicionamiento ambiental peculiar, de carácter únicas.

Urbanamente, la ubicación del conjunto es relevante; por su accesibilidad, cercana a dos estaciones del metro (estaciones de Metro San Miguel y El Llano), inmediata a la Gran Avenida José Miguel Carrera, en alcance de diversos medios de transporte, posee un valor como espacio de uso público.

Desde una imagen urbana, las cavas han contribuido a la conformación más que de una imagen, de una memoria urbana que se ha instalado como un elemento de identidad de los habitantes de la comuna. Un inmueble, especialmente valorado por la comunidad en circunstancias que el auge inmobiliario ha
7. El Llano Subercaseaux y su presencia urbana en relación a la ubicación de las cavas. Archivo del autor.

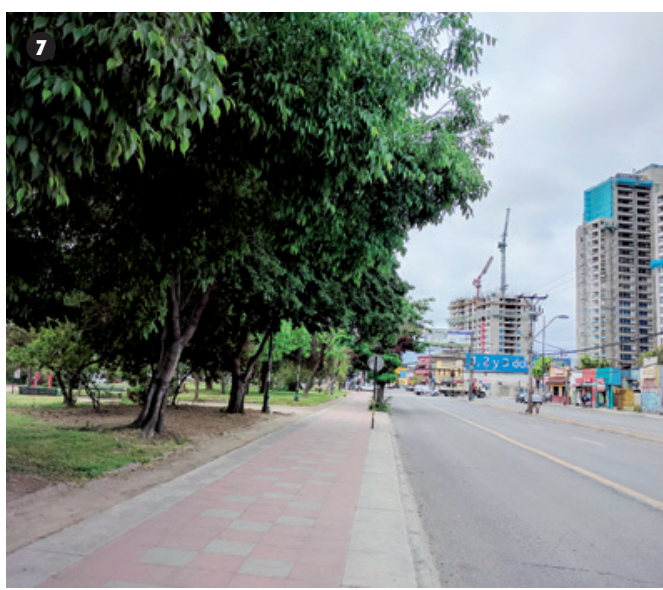

cambiado la escala de las edificaciones, y el aspecto general del sector, especialmente en las inmediaciones de la vía principal que es la Gran Avenida.

No habiendo sido un inmueble visitable, por haber sido propiedad privada de carácter industrial, la conciencia de su existencia actúa como una presencia que acompaña la identidad comunal, sin estar necesariamente medida por la experiencia de conocer las edificaciones empíricamente. Esto determinó en su momento, la confusión entre las edificaciones enterradas, y la fachada de las bodegas sobresuelo de la Viña, como componentes fundamentales remanentes del complejo, anteponiéndose y casi superando equívocamente las cavas enterradas.

\section{DIAGNÓSTICO}

Antes del actual destino inmobiliario residencial del predio, este se destinó a almacenaje y distribución, no existiendo acceso por parte del público general. En la superficie se instalaron diversos galpones, de distintas etapas y un patio de asfalto y hormigón destinado a maniobras de camiones. Una situación, donde el uso, si bien era preferible al abandono, no aportada mayor conocimiento de las bodegas enterradas, o vitalidad urbana al sector. Al entierro real se superpone el obstáculo visual, la inaccesibilidad.
8. Vista interior de una cava, despejada de los vestigios de barricas y sometida a proceso de impermeabilización. Se aprecia calidad constructiva de la albañilería. Archivo del autor.

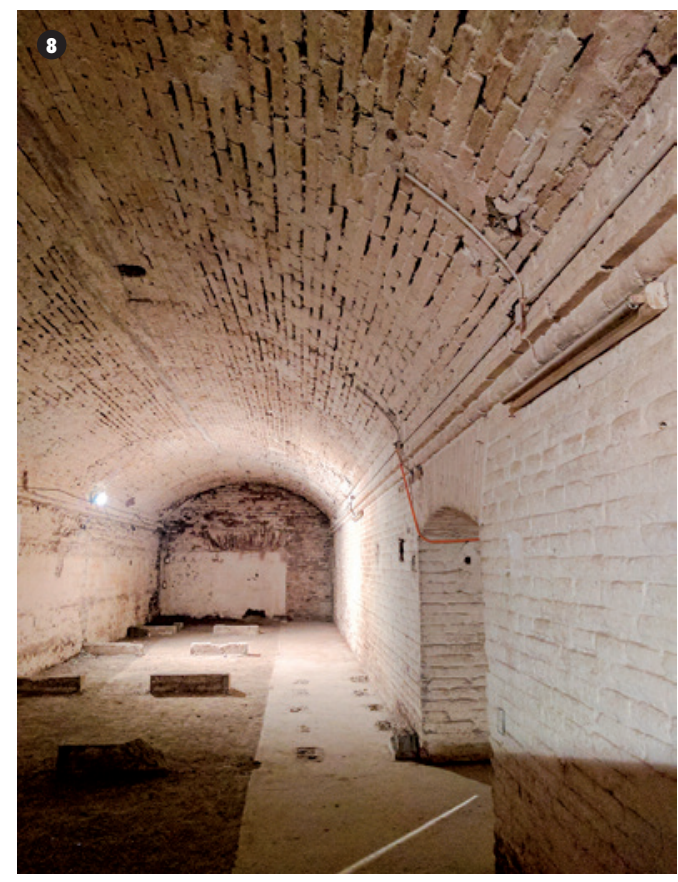

Estructuralmente, el análisis de la edificación concluyó que los muros y bóvedas de albañilería de ladrillo artesanal se encontraban en buen estado, no tenían riesgo de estabilidad, y por ello ninguna necesidad de refuerzos. No obstante, las obras de construcción del proyecto inmobiliario afectaron indirectamente a las cavas, por diversas faenas secundarias, inmediatamente vecinas al inmueble patrimonial.

El perímetro de la estructura de albañilería debió reforzarse con pilotes de hormigón armado para permitir la construcción de estacionamientos del conjunto, situación no exenta de riesgo, y que implicaba también un protocolo controlado de construcción de los refuerzos.

El proyecto inmobiliario, aún en construcción, convivirá con el espacio público constituido por la rehabilitación de las cavas. La parte en superficie, exterior, -o la techumbre de las cavas- se utilizaría como espacios comunes, como jardines y patios, del conjunto habitacional, destino que implicaba impermeabilizar dicho patio para que el agua lluvia y el riego no aportaran humedad que 
9. Pilas de fundación para estacionamientos y refuerzo del muro longitudinal cavas. Archivo del autor.

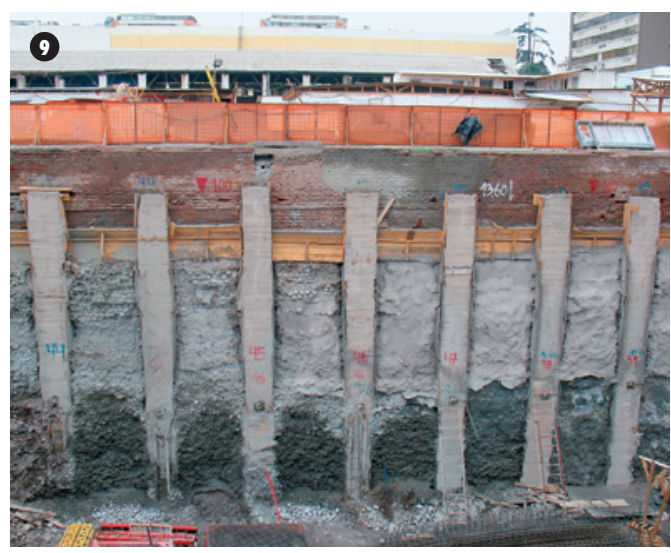

afectara negativamente a las cavas. Aunque ambientalmente la situación subterránea del inmueble permitía una aislación acústica y térmica notable, esto había sido distorsionado por diversos cierros y modificaciones interiores, anteriores a la compra, entre los cuales estaba la obstrucción de puntos de ventilación.

Otro factor relevante en el diagnóstico fue la condición de accesibilidad de las cavas. Fruto de las intervenciones posteriores anteriores a la última compra, las cavas no tenían un acceso definido arquitectónicamente. Esto, en parte porque se había destinado la superficie a galpones y bodegas. Solo existía una entrada mediante una escalera de hormigón.

Finalmente, el interior había sido profusamente intervenido existiendo aparejos de albañilería a la vista, otros pintados, exclusas para la entrada de barricas tapeadas, y separaciones de losas de hormigón armado verticales y horizontales, instalaciones eléctricas de antigua data, entre otros. De los anteriores, las separaciones de hormigón resultaban de difícil reversión, por las vibraciones asociadas a su demolición.

Los antecedentes configuraban un desafiante punto de partida para una adecuada puesta en valor del conjunto, al que se sumaba, además de las acostumbradas restricciones presupuestarias, de manera anecdótica-pero no menor- el hecho de que en el interior del recinto quedaron diversas barricas de guarda vacías, sin
10. Acceso desde escalera exterior. Archivo del autor.

11. Detalles de instalaciones eléctricas existentes previas al desarrollo del proyecto. Archivo del autor. 12 y 13. Vista de las cavas y las barricas dispuestas en vista a su conservación. Archivo del autor.
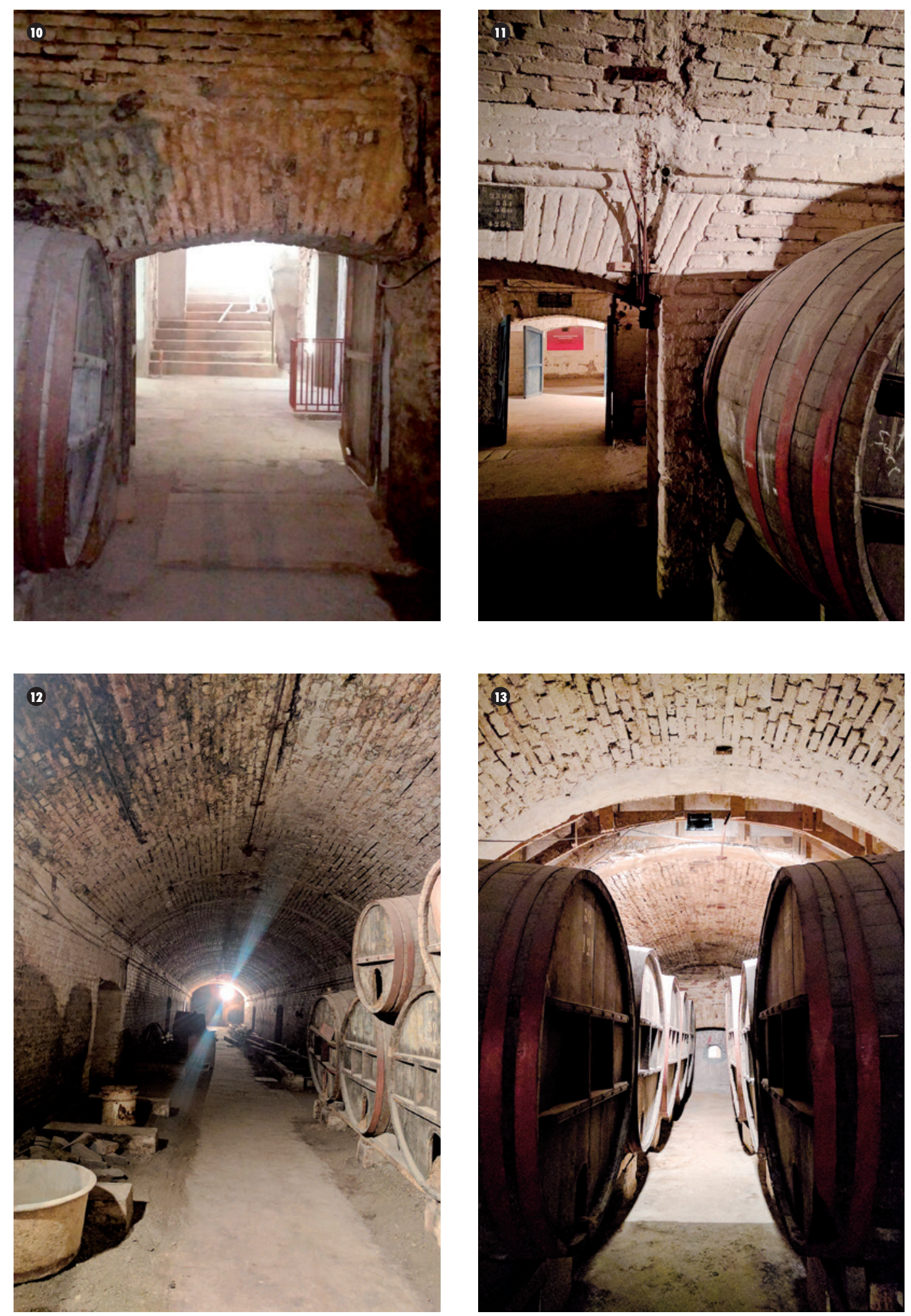
14. Croquis de distribución programática. Archivo del autor.

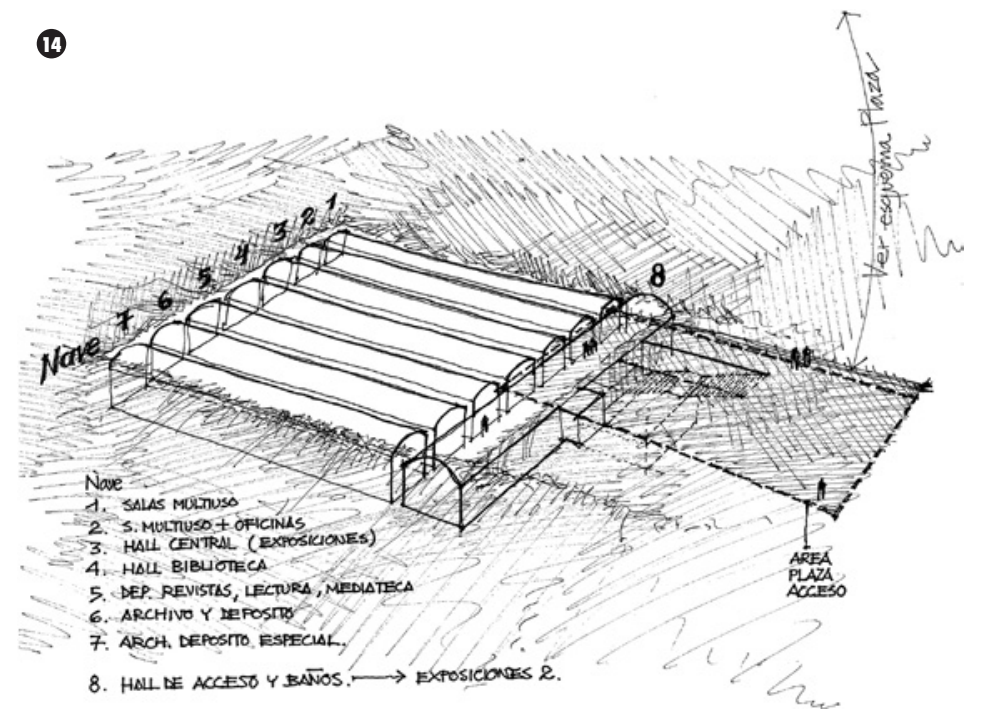

la posibilidad de sacarlas sin desarmarlas, dado que todos los vanos remanentes resultaban de menor dimensión que las barricas.

\section{CRITERIOS DE INTERVENCIÓN}

La entidad administrativa a cargo del inmueble de las bodegas enterradas, proyectó la puesta en valor propendiendo a usos dignos y vinculados al potencial cultural que las cavas presentaban, siendo coincidente con una necesidad efectiva de la comunidad, restándose de eventos o espectáculos de interés comerciales. Esta decisión implicó un compromiso con que las intervenciones no desvirtuasen los valores arquitectónicos del inmueble.

La determinación de un proyecto de intervención comenzó con la definición de un programa, considerando que la función se plantearía como un elemento relevante en la integración de las cavas a la vida urbana (Villagrán, 1989), decisión que originó una consulta a los requerimientos de orden educativo cultural, de la comuna, estableciendo un futuro programa basado en una biblioteca principal y salas de exposiciones. Este programa fue afín a la estructura espacial de las cavas, constituidas por 7 bodegas abovedadas de $48 \times 6$ metros,

15. Croquis de elementos de intervención. Archivo del autor.

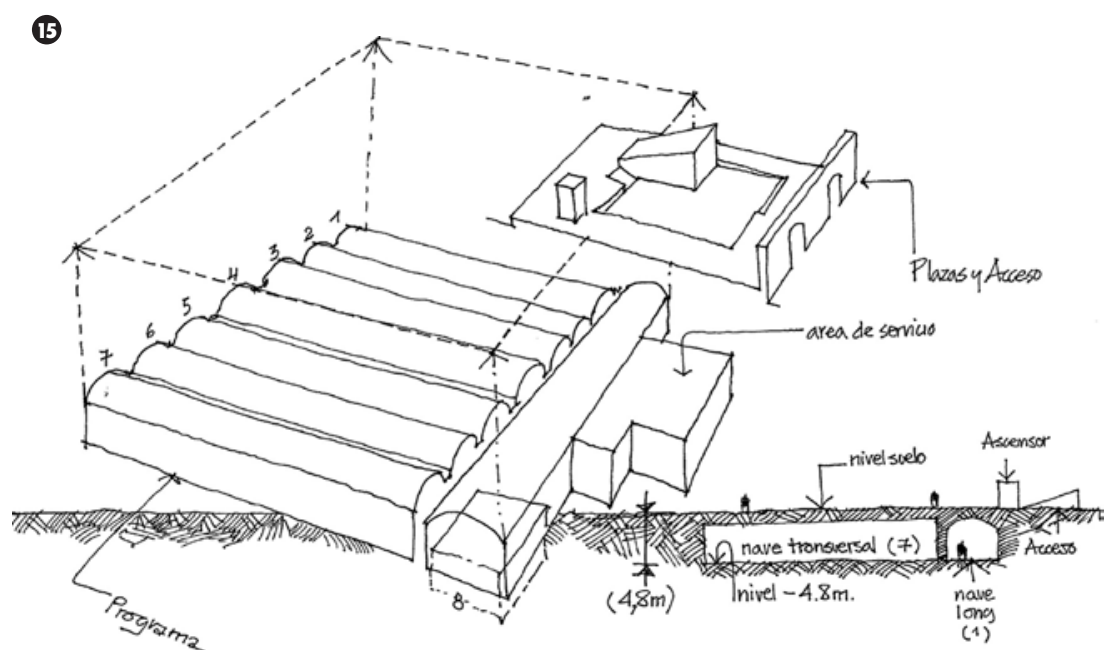

conectadas entre sí transversalmente cada 10 metros, que se prestaban para generar espacios relativamente flexibles y de uso diverso, permitiendo algunas configuraciones para usos masivos o grupales, sumando y subdividiendo espacios.

En términos físicos y de acondicionamiento ambiental, se acogió un criterio conservacionista privilegiando la preservación del devenir natural material de las cavas, como elemento estético (Zumthor, 2014) y reconociendo la condición de continuidad histórica del inmueble para la comuna. La operatividad de las futuras nuevas actividades requerirá de instalaciones y redes, que fueron incluidas considerando su disposición a la vista, reconociendo también la vinculación a una tipología industrial. Su disposición fue proyectada con mucho detenimiento en sus condiciones de presentación y los tipos de equipos utilizados.

En lo estructural, si bien resultaba recomendable liberar todas las divisiones de hormigón armado, su total eliminación, esto conllevó un riesgo, por las vibraciones asociadas a la premura de un cronograma de obra rígido, en la estructura de albañilería original. Por ello, se optó por eliminar todas las losas interiores y conectar mediante vanos las divisiones verticales, más que eliminarlas. Igualmente hubo divisiones interiores que eran fruto del proceso industrial en su evolución posterior a la construcción de las cavas, los cuales se conservaron.

Operativamente y en términos de diseño, para la generación del nuevo acceso se decidió aprovechar la escalera ya existente, aunque externa al origen, pero en hormigón armado y de dificultosa demolición. Esta se combinó con el reciclaje de un portillo para la bajada de barricas en la cual se edificó una segunda escalera de público.

De esta manera, se definieron nuevas circulaciones verticales que abrazarían un patio semihundido bajo el cual, en una altura más convencional, se dispusieron los servicios para el uso público, que no resultaba recomendable ubicar al interior de las cavas mismas, por el potencial deterioro asociado a la inclusión de nuevas instalaciones de agua potable y alcantarillado, en una construcción centenaria.

Con respecto a las terminaciones de superficie, si bien resultaba interesante, desde una mirada estético-arquitectónica convencional, el remover revestimientos y pátinas dejando las albañilerías a la vista, ello implicaba un proceso manual de largo aliento, sin la posibilidad de remover 
16. Vista de la cava transversal de acceso en sus distintos estados de intervención. Archivo del autor.
17. Tabique divisorio elaborado con maderas de los soportes en desuso de la zona de las barricas. Archivo del autor.
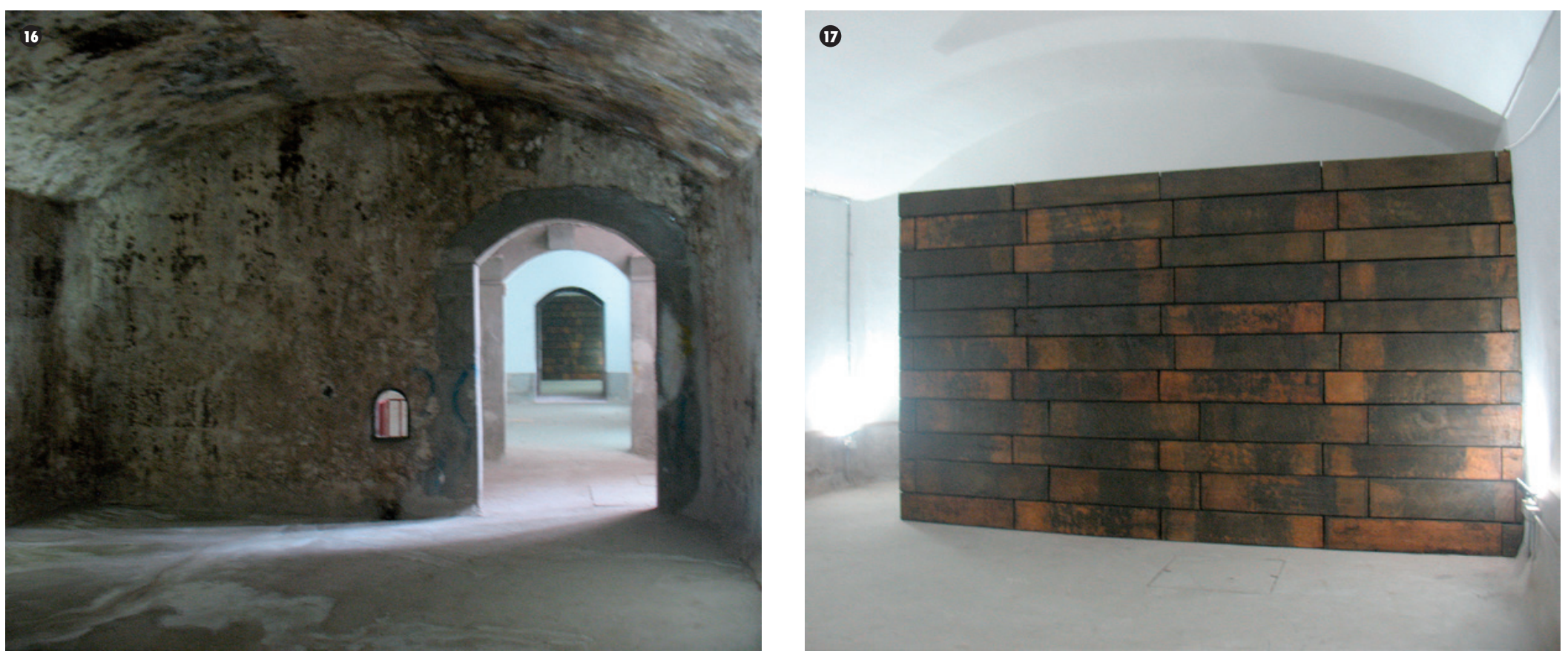

las partículas de ladrillo y pintura de manera fácil, o incluso posible, con el letargo asociado en el desarrollo de otras partidas. Se optó, en cambio, por liberar esto a las etapas sucesivas de la obra, reservando tres cavas que debían permanecer en su condición original como una muestra del estado original encontrado, cercano al origen constructivo del inmueble, resguardando el pasado.

\section{DISCUSIÓN. CONTINUIDAD \\ DEL PROYECTO Y CRITERIOS PARA LA JERARQUÍA DE SU MATERIALIZACIÓN}

Dada la ubicación del inmueble, el impacto de una concurrencia masiva podría generar un círculo de vitalidad urbana, que ya estaba apoyada por la existencia (a 100 metros del acceso) del centro comercial asociado; el Hospital Roberto del Río y la propia Municipalidad de San Miguel, entre otros. En este sentido, el potencial de un espacio cultural público en ese emplazamiento es relevante para la vida de la comunidad, toda vez que prácticamente se garantiza la concurrencia.
No obstante, entre las mayores dificultades para un adecuado desarrollo del proyecto, cabe señalar primeramente, la de reconvertir un espacio cerrado de uso industrial, concebido para barricas de vino, en un lugar habitable para las personas, con todas las implicancias de control de clima asociada: irradiación de calor, consumo de aire, entre otros. En este sentido, la inclusión de un acondicionamiento ambiental artificial mediante equipos de aire es un pie forzado, no tanto por la temperatura, de escasa variación, si no por la renovación del aire de frente al paso y estadía de personas en la otrora cava de vinos.

Una segunda dificultad la revestía el paso de un espacio privado, parte integrante de un condominio, a un espacio público, con lo que el uso público del espacio cedido a la municipalidad debió ser incorporado dentro del reglamento de copropiedad en lo referente a horarios de funcionamiento y algunas restricciones al uso.

Lo anterior a menudo soslaya, para contextos como el latinoamericano, y el chileno en particular, la condición espurea y adaptativa de la producción arquitectónica local, especialmente la histórica -Colonia y siglo XIX-, donde el componente sísmico y la adopción de soluciones locales que hacen la mímica de materiales y técnicas del antiguo continente, como reacción a la escasez de recursos son muy difundidos. Para el caso de las cavas esto redundó en la elección de técnicas y materiales que se estimaron adecuados y afines a un criterio de conservación.

\section{CONCLUSIONES}

En la actualidad en Chile, muy a menudo se presenta la disyuntiva entre patrimonio y desarrollo comercial inmobiliario privado, como un diálogo sordo, debiendo sacrificarse uno en pos del otro, estableciéndose una siniestra alternancia, que polariza posiciones en términos muchas veces irreconciliables, generando por una parte una nueva arquitectura que no densifica la continuidad histórica por una parte o bien eternizando en su condición museística un patrimonio que no se integra a la vida urbana. 
18. Croquis de la plaza de acceso de la intervención de las cavas. Archivo del autor

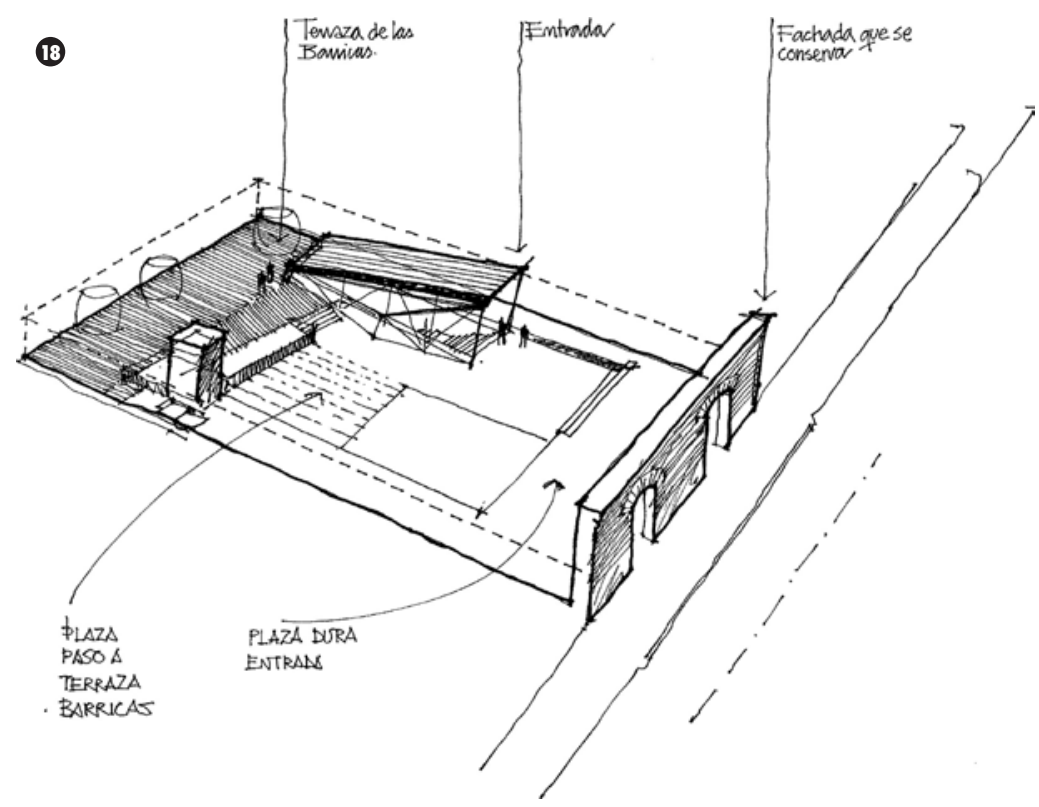

19. Croquis de la plaza de acceso de la intervención de las cavas. Archivo del autor.
Por otra parte, tal disyuntiva a menudo se plantea en casos de patrimonio arquitectónico postergado, olvidado o incluso subvalorado, que ante alguna intervención adquieren, para la comunidad en la que el objeto material se inserta, una renovada vigencia, ante la amenaza de su desaparición, situación que moviliza a comunidades otrora pasivas.

El ejemplo de las cavas aquí referidas, es en este sentido, típico. Igualmente demuestra que por el contrario del prejuicio tanto de conservacionistas como de neófilos, se pueden integrar a la vida contemporánea, las obras provenientes de una pasado que otorgan densidad y continuidad histórica a la ciudad, mediante una gestión integradora de la institucionalidad normativa pública y el interés privado asumiendo el componente patrimonial como un determinante relevante que no debe ser soslayado.

Uno de los mayores desafíos del sector privado inmobiliario en su conjunto es dejar de ejercer un rol pasivo, en muchos casos "victimizado" por las comunidades y especialistas en patrimonio para abordar el componente patrimonial de los proyectos de manera más informada, realista y estratégica.
Para poder ejecutar la puesta en valor de las cavas fue fundamental un acercamiento franco y práctico con una atenta lectura de los objetivos de uno y otro, como fue el caso del privado -el propietario-, y el público -la municipalidad-. Comprender igualmente que donde el objetivo de uno fue maximizar las utilidades del terreno conforme a las posibilidades normativas existentes; el objetivo del otro fue procurar un espacio o instancia que aportara una mejora de la calidad de vida de la comunidad. Más que intereses contrapuestos, devenidos en intereses de dimensiones distintas, paralelas del quehacer.

Un segundo aspecto interesante de corroborar al momento de la intervención es la necesidad de entender la naturaleza del patrimonio arquitectónico nacional, en sus similitudes y diferencias con el patrimonio europeo que inspira gran parte de las cartas de navegación internacionales, contexto en el cual la condición sísmica local resulta extremadamente relevante. Por ejemplo, entender la diferencia de marcos normativos, posibilidades presupuestarias y modificaciones tecnológicas locales. En la realidad chilena, si bien ha habido grandes avances se está aún lejos de tener normas específicas y un abanico de mecanismos de financiamientos e incentivos adecuados para la recuperación del patrimonio arquitectónico. Esto es, sin contar la adecuada articulación aún deficiente- entre los diversos instrumentos emanados de distintos organismos del Estado.

En tercer lugar, la comprensión del ámbito de la producción material de la arquitectura, en donde el contratista pueda garantizar mejores plazos de ejecución y un control presupuestario más exacto.

Los aspectos anteriores convergieron y fueron ponderados en la puesta en marcha de un proceso de puesta en valor para las cavas que se presenta en desarrollo aunque aún inconcluso en su materialización dependiente de la continuidad de las gestiones conjuntas. Sin embargo, desde su génesis, en un medio altamente tensionado por los privados en la búsqueda de oportunidades comerciales, y las comunidades en la defensa de su medio ambiente, las cavas surgen como una posibilidad de puesta en valor poco explorada hasta ahora. 
20. Croquis de la vista interior de la intervención de las cavas. Archivo del autor.
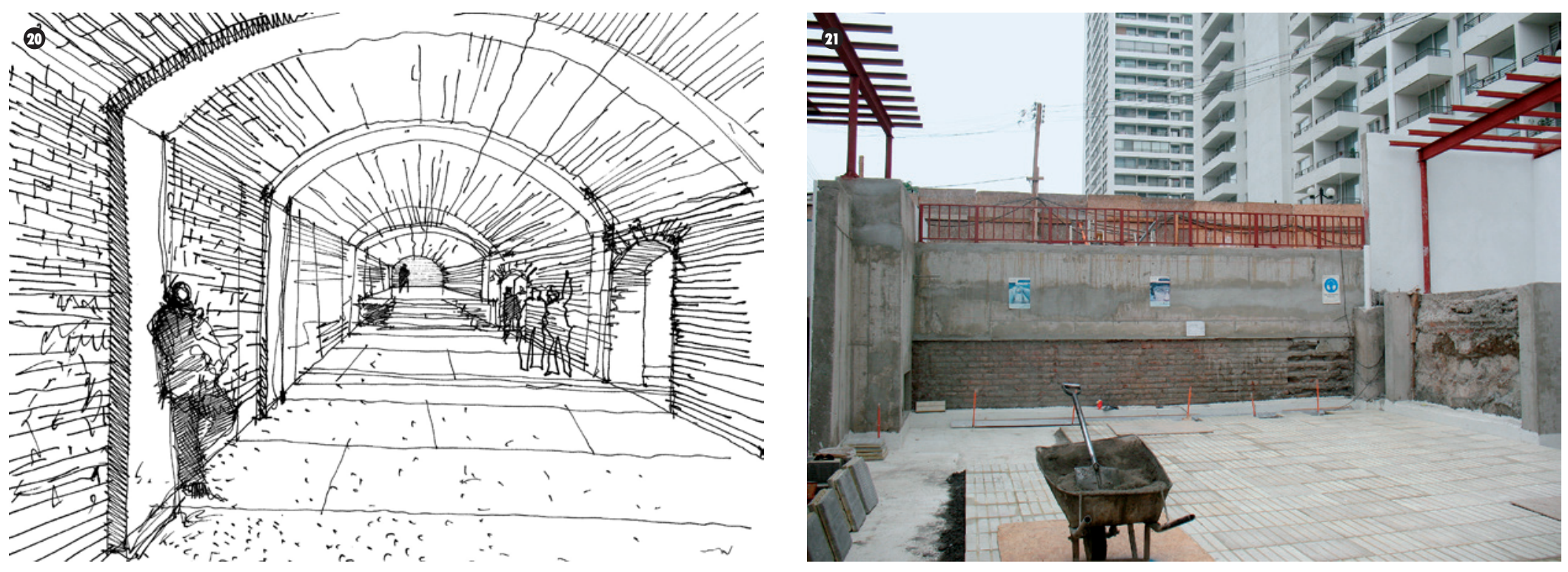

\section{REFERENCIAS BIBLIOGRÁFICAS}

Consejo de Monumentos Nacionales, CMN (2015). Documentos de ICOMOS. Santiago: CMNICOMOS.

Ceballos, G. (2014). Chile país de Vino. Historia de la Industria Vitivinícola 1492-2014. Santiago: Universitaria.

Del Pozo, J. (2014). Historia del Vino Chileno. Santiago: LOM Ediciones.

Frampton, K. (1999) Estudios sobre cultura tectónica. Poética de la construcción en la arquitectura de los siglos XIX y XX. Madrid: Akal.
21. Vista de la edificación de la segunda escalera, agregada al esquema original de acceso de las cavas, se aprecia asimismo el patio de acceso semihundido que media en nivel convencional del suelo y la cota inferior de las cavas. Se observa también su vinculación espacial con el conjunto habitacional. Archivo del autor.
Guilisasti, S. \& Subercaseaux, F. (1987). Chile y su vino. Santiago.

Pizzi, M.; Valenzuela, M. P. \& Benavides, J. (2009). El Patrimonio Industrial en torno al Ex Ferrocarril de Circunvalación de Santiago. Santiago: Universitaria.

Rossi, A. (1982). Arquitectura de la ciudad. Barcelona: Gustavo Gili.

Subercaseaux, R. (1936). Memoria de ochenta años: recuerdos personales, críticas, reminiscencias históricas, viajes, anécdotas. Santiago: Nascimiento
UNESCO (1994). Documento de Nara sobre la Autenticidad. Japón, agencia de Asuntos Culturales.

Villagrán García, J. (1989). Teoría de la arquitectura Ciudad de México: Universidad Autónoma de México.

Zumthor, P. (2006). Atmósferas, entornos arquitectónicos. Barcelona: Gustavo Gili.

Zumthor, P. (2014). Pensar la arquitectura. Barcelona: Gustavo Gili. 